\title{
Autumnalamide targeted proteins of the immunophilin family
}

\author{
Jon Andoni Sánchez ${ }^{a}$, Amparo Alfonso $^{a}$, Olivier P. Thomas ${ }^{\mathrm{b}, \mathrm{c}}$, Luís M. Botana ${ }^{\mathrm{a}, *}$ \\ a Departamento de Farmacología, Facultad de Veterinaria, Universidad de Santiago de Compostela, Lugo 27002, Spain \\ b Geoazur, UMR Université Nice Sophia Antipolis-CNRS-IRD-OCA, 250 rue Albert Einstein, 06560, Valbonne, France \\ ${ }^{\mathrm{c}}$ Marine Biodiscovery, School of Chemistry, National University of Ireland Galway, University Road, Galway, Ireland
}

Previous works with autumnalamide reported that Store Operated Calcium (SOC) channels were blocked through mitochondrial modulation. In the present paper we studied the effect of autumnalamide on ion-omycin $\mathrm{Ca}^{2+}$ fluxes. Thus, autumnalamide did not modify ionomycin-sensitive intracellular pools while the ionomycin-induced $\mathrm{Ca}^{2+}$ influx was blocked with similar potency whether the incubation was done before or after ionomycin-sensitive pools depletion. Nevertheless, autumnalamide was not able to inhibit ionomycin-induced $\mathrm{Ca}^{2+}$ influx once the membrane channels were activated. Moreover, the compound efficiently inhibited flufenamic acid (FFA) $\mathrm{Ca}^{2+}$ release induced in this organelle but no the next influx. Since in previous work the effect of autumnalamide was inhibited by cyclosporine A (CsA), structures that target this drug were studied. Therefore, the affinity of autumnalamide for cyclophilin D (Cyp D) was examined. The $K_{\mathrm{D}}$ obtained for Cyp D- autumnalamide was $1.51 \pm 1.399$. Moreover, the $K_{\mathrm{D}}$ for Cyp Aautumnalamide was calculated. The peptide had a similar order of Cyp A binding affinity than CsA ( $8.08 \pm 1.23$ and $6.85 \pm 1.1 \mu \mathrm{M}$ respectively). After testing autumnalamide-binding capacity for Cyp A, the activity of this compound on Cyp A pathway was tested. Thus, the effect on interleukin (IL)-2 release on activated T-lymphocytes was checked. Autumnalamide was able to reduce IL-2 levels near to T cells in resting conditions. Next, the effect over calcineurin and NFATc1 was also evaluated. While CsA inhibits both calcineurin and NFATc1, autumnalamide did not produce any effect. From these results we can con-clude that, autumnalamide targeted mitochondrion and prevent T-cells from IL-2 production through the modulation of SOC $\mathrm{Ca}^{2+}$ channels.

\section{Introduction}

Filamentous cyanobacteria of the genus Phormidium have a worldwide distribution and present a large chemical diversity with nearly 200 described species. The genus Phormidium forms mats on wet soil, mud, wetted rocks, macrophytes and in standing and running waters. Up to now, several species from different genus have been cultivated for the production of large quantities of biomass with wide range of applications, including animal and human nutrition, as biofertilizers in agriculture, cosmetics or with energy purpose to produce biodiesel (Markou and Georgakakis, 2011). Nevertheless, the use of active metabolites in the pharmaceutical sector is less studied. In the case of cyanobacteria, the production of toxic metabolites with therapeutic potential has

\footnotetext{
* Corresponding author.

E-mail addresses: jonandoni.sanchez@rai.usc.es (J.A. Sánchez), amparo.alfonso@usc.es (A. Alfonso),olivier.thomas@nuigalway.ie (O.P. Thomas), Luis.Botana@usc.es (L.M. Botana).
}

attracted the attention of pharmacy industry (Coates et al., 2013). Autumnalamide is a prenylated cyclic peptide obtained from the cyanobacteria Phormidium autumnale whose chemical structure has been recently elucidated (Fig. 1) (Audoin et al., 2014). This specie is one of the most common of the genus Phormidium, which colonizes stones in streams and rivers (Komárková, 2003). Initial studies on the biological activity of this natural compound has shown that autumnalamide is able to induce calcium influx blockade through store operated calcium channels (SOC channels) in SH-SY5Y neuroblastoma cells due to an effect at the mitochondrial level, disrupting the mitochondrial membrane potential (MMP) and inducing the opening of mitochondrial permeability transition pore (mPTP). Moreover, the effect of autumnalamide on SOC channels was abolished by pre-incubation with the immunosuppressant drug cyclosporine A (CsA), (Audoin et al., 2014). The mPTP complex is a multiproteic structure composed by different proteins. Among them, cyclophilin D (Cyp D) is an essential component with a molecular weight of $22 \mathrm{kDa}$ (Elrod and Molkentin, 2013; Javadov and Kuznetsov, 2013). CsA is a cyclic 11-amino-acid peptide isolated from the fungus Tolypocladium inflatum and was described as 
a potent and selective MPTP inhibitor due to Cyp D binding in the matrix and on the inner surface of the mitochondrial membrane (Elrod and Molkentin, 2013; Hoppert et al., 2001). Besides Cyp D binding and mPTP opening inhibition, CsA has the ability to bind to all Cyclophilins (Cyps) present in the cell with different affinities due to a high degree of sequence conservation in their structure (Wang and Heitman, 2005; Fruman et al., 1994). The Cyps protein family structurally contain two main protein domains, a cyclophilin (Суp)-like domain, which is the conserved domain across all family members and the specific domain depending on the family member (Lee and Kim, 2010). These proteins are present in all eukaryote and prokaryote cells like plants, fungi, bacteria, insects and human cells with a common peptidyl-prolyl isomerase activity. That is, Cyps catalyze the isomerisation of the peptide bonds from trans to cis form at the proline residues and facilitates protein folding among other functions (Wang and Heitman, 2005; Kofron et al., 1991; Davis et al., 2010). The location of these proteins is very broad and can be found in different organelles and also in the cytosol or in the extracellular medium (Lee and Kim, 2010; Kumari et al., 2013). Our initial studies on the biological activity of autumnalamide have shown that the compound induced the formation of MPTP. The MPTP can be induced by different stimulus over the proteins that form this structure like Cyp D (Audoin et al., 2014). Due to this and since the effect of autumnalamide on SOC channels was blocked by CsA, the main objective of this work was to go into detail about the knowledge of mechanism of action of autumnalamide.

\section{Materials and methods}

\subsection{Chemicals and solutions}

Carboxymethyl dextran (CM5) sensor chips, Hank's Balance Solution Surfactant P20 (HBS-EP) buffer (pH 7.4, 0.01 M 4-(2-hydroxyethyl)-1-piperazineethanesulfonic acid (HEPES), $0.15 \mathrm{M} \mathrm{NaCl}, 3 \mathrm{mM}$ Ethylenediamine tetracetic acid (EDTA), $0.005 \%$ polysorbate), amine coupling kit (1-ethyl-3- (3dimetylaminopropyl) carbodiimide hydrochloride (EDC) and $\mathrm{N}$-hydroxysuccinimide (NHS) and ethanolamine- $\mathrm{HCl}$ were supplied by BiacoreAB (Uppsala, Sweden). Percoll was obtained from Pharmacia (Uppsala, Sweden). Plastic tissue-culture dishes were purchased from Falcon (Madrid, Spain). RPMI and Foetal calf serum (FBS) were bought from Gibco (Glasgow, UK). The Pan T cell Isolation Kit (human) and the monoclonal antibody to human CD3, clone BW264/56, FITC ware purchased from Miltenyi Biotec (Germany). Human interleukin (IL)-2 ELISA kit was obtained from Invitrogen (Spain). Active human Cyclophilin D (Cyp D) and Active Human Cyclophilin A (Cyp A) full-length proteins were from Abcam (Cambridge, UK). Anti-nuclear factor of activated $\mathrm{T}$ cells (NFAT) c1 mouse monoclonal antibody [AT1C3] to NFATc1 and rabbit polyclonal anti-lamin B1 antibody were from Abcam (UK). FURA-2AM was obtained from Molecular Probes. Polyvinylidene fluoride (PVDF) membrane was from Millipore (Temecula, CA). Polyacrylamide gels and molecular weight marker Precision Plus Protein Standards Kaleidoscope was from BioRad (Barcelona, Spain). The Protease Inhibitor Complete Tablets and Phosphatase Inhibitor Cocktail Tablets were from Roche (Spain). Bovine serum albumin (BSA) and CsA (purity $\geq 98.5 \%$ ), Flufenamic acid (FFA), carbonyl cyanide 4-(trifluoromethoxy) phenylhydrazone (FCCP) and the rest of Chemicals and reagents were obtained from SigmaAldrich (Madrid, Spain). The strain of Phormidium autumnale was purchased from the Culture Collection of Algae and Protozoa (UK, CCAP1446/10). The strain was cultured and extracted as previously described (Audoin et al., 2014). Autumnalamide was isolated with purity higher than $95 \%$ as demonstrated by its ${ }^{1} \mathrm{H}$ NMR spectrum. The composition of saline solution (PBS) used for

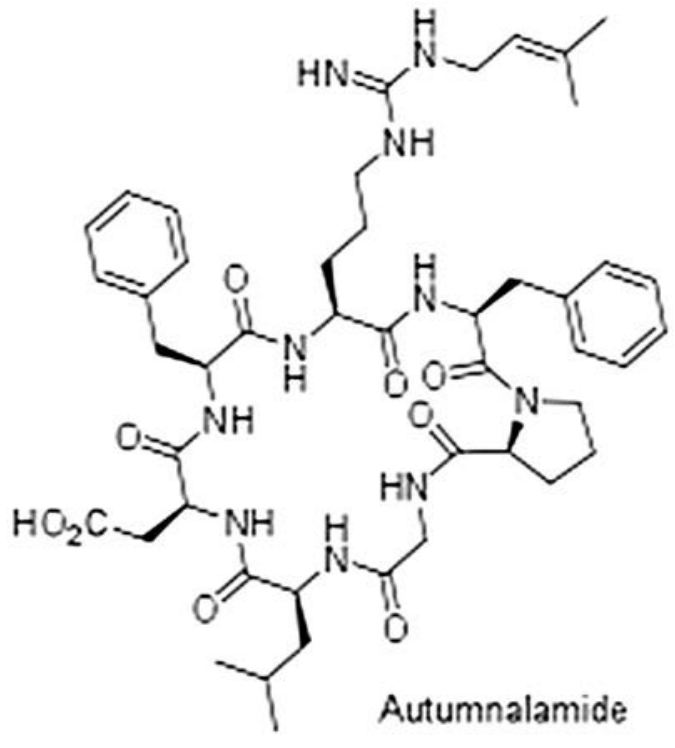

Fig. 1. Autumnalamide chemical structure.

human $\mathrm{T}$ lymphocytes purification was in $(\mathrm{mM})$ : $137 \mathrm{ClNa}, 8.2$ $\mathrm{Na}_{2} \mathrm{HPO}_{4}, 1.5 \mathrm{KH}_{2} \mathrm{PO}_{4}, 3.2 \mathrm{KCl}$ and 2 EDTA. The composition of Umbreit saline solution was in $(\mathrm{mM}): 119 \mathrm{NaCl}, 1.2 \mathrm{Mg}\left(\mathrm{SO}_{4}\right), 1.2$ $\mathrm{NaH}_{2} \mathrm{PO}_{4}, 22.8 \mathrm{NaHCO}_{3}, 5.9 \mathrm{KCl}, 1 \mathrm{CaCl}_{2}$ and $1 \mathrm{~g} / \mathrm{L}$ Glucose. The $\mathrm{pH}$ was equilibrated between 7.2-7.3. Stock solutions of drugs were done in dimethylsulphoxide (DMSO).

\subsection{Human neuroblastoma culture cells and human $T$ lymphocytes isolation}

Neuroblastoma cell line SH-SY5Y was purchase from American Type Culture Collection (ATCC) Number CRL-2266. The cells were plated in $25 \mathrm{~cm}^{2}$ flasks at a cultivation ratio of $1: 10$. The cells were maintained in Eagle's Minimum Essential Medium (EMEM) from ATCC and F12 Medium (Invitrogen) 1:1 supplemented with $10 \%$ fetal bovine serum (FBS) (Gibco) plus $100 \mathrm{UI} / \mathrm{mL}$ penicillin and $100 \mu \mathrm{g} / \mathrm{mL}$ streptomycin. The neuroblastoma cells were expanded weekly using 0,05\% trypsin/EDTA (1x) (Invitrogen).

Peripheral lymphocytes were isolated from human fresh heparinised blood from healthy volunteers as previously described (Alfonso et al., 2001). The blood was diluted in the same proportion with PBS plus EDTA $2 \mathrm{mM}$ previously equilibrated at room temperature. $4 \mathrm{~mL}$ of diluted blood were placed over $3 \mathrm{~mL}$ of isotonic percoll $(57,5 \%)$ carefully avoiding the mixture of the two phases. Once the tubes were prepared they were centrifuged at $3000 \mathrm{rpm}$, $25 \mathrm{~min}$ at room temperature. After centrifugation, different phases were obtained and only the fraction that containing the population of white blood cells was collected and washed three times by centrifugation with PBS-EDTA at $1500 \mathrm{rpm}, 10 \mathrm{~min}$, room temperature to remove remaining percoll. Lymphocyte purity was always higher than $80 \%$. T lymphocytes were purified from this population with a human Pan T cell Isolation Kit. This is an indirect magnetic labeling system for the isolation of untouched T cells. T cell purity was always higher than 95\%. Assessment of cell purity was performed by flow cytometry by using a monoclonal antibody to human CD3 labeled with FITC. Viability (>95\%) was determined by trypan blue exclusion. Pure T cells were maintained in RPMI 1640 plus $10 \%$ FBS and plated in 24 plastic tissue-culture dishes in humidified $5 \% \mathrm{CO}_{2}$ and $95 \%$ air atmosphere at $37^{\circ} \mathrm{C}$. 


\subsection{Measurements of cytosolic free calcium}

Cells were seeded onto $18 \mathrm{~mm}$ glass cover slips and used between 48 and $72 \mathrm{~h}$ after plating at a density of 120.000 cells/glass cover slip. For cytosolic $\mathrm{Ca}^{2+}$ measurements, cells were washed twice with saline solution (Umbreit) supplemented with $0.1 \%$ BSA. Umbreit composition was (mM): $\mathrm{NaCl} 119, \mathrm{Mg}\left(\mathrm{SO}_{4}\right) 1.2, \mathrm{NaH}_{2} \mathrm{PO}_{4}$ 1.2, $\mathrm{NaHCO}_{3} 22.85, \mathrm{KCl} 5.94$, Glucose $0.1 \%$ and $\mathrm{CaCl}_{2}$ 1. In all assays the solutions were equilibrated with $\mathrm{CO}_{2}$ before being used, adjusting the final $\mathrm{pH}$ between 7.2-7.4. The cells were loaded with the $\mathrm{Ca}^{2+}$-sensitive fluorescent dye FURA-2 AM $(0,5 \mu \mathrm{M})$ for $6,5 \mathrm{~min}$ at $37^{\circ} \mathrm{C}$ and $300 \mathrm{rpm}$. Loaded cells were washed twice with saline solution and the cover slips were placed in a thermostatic chamber (Life Sciences Resources, UK). Cells were viewed using a Nikon Diphot 200 microscope equipped with epifluorescence optics (Nikon 40X- immersion UV- Fluor objective). Addition of drugs was made by aspiration and addition of fresh bathing solution with the drug to the incubation chamber. Cytosolic $\mathrm{Ca}^{2+}$ levels as FURA-2 ratio was obtained from the images collected by fluorescent equipment, Ultra-high-speed wavelength switching illumination system (Lambda-DG4) for excitation and Lambda 10-2 for emission from Sutter Instruments Co., USA. The Light source was a xenon arc bulb and the different wavelengths used were chosen with filters. Cells were excited at 340 and $380 \mathrm{~nm}$ lights alternately and emission was collected at $510 \mathrm{~nm}$.

\subsection{Viability assay}

Cells were incubated with different concentrations of autumnalamide ranging from 0.001 to $10 \mu \mathrm{M}$ for 24 and $48 \mathrm{~h}$. After incubation, cells were washed twice with saline solution. MTT $\left(500 \mu \mathrm{g} \mathrm{mL}^{-1}\right)$ dissolved in saline solution was added to the 96well microplate for $1 \mathrm{~h}$ at $37^{\circ} \mathrm{C}(300 \mathrm{rpm})$ in the dark. Finally the MTT incubation media was removed and cells were washed once before the addition of SDS at 5\%. Colored formazan salt aggregates were measured at $595 \mathrm{~nm}$ in a spectrophotometer plate reader.

\subsection{Binding experiments: surface activation, ligand immobilization and binding}

A Biacore X SPR biosensor with Control Software and BIAevaluation software version 3.0 from Biacore (GE Healthcare, Uppsala, Sweden) was used to check the binding between molecules. Sensor surface activation and ligand immobilization were performed by using HBS-EP as running buffer at a flow rate of $5 \mu \mathrm{L} \mathrm{min}^{-1}$ and $25^{\circ} \mathrm{C}$. CM5 sensor chip were used as surface where Cyp D or Cyp A was immobilized as ligand. The CM5 chip is a glass slide coated with a thin layer of gold with a matrix of carboxymethylated dextran covalently attached. The CM5 chip was activated using an amine coupling kit. Following manufacture instructions, a mixture $(1: 1, v / v)$ of EDC and NHS was applied for 2 min over the sensor chip. After activation, the ligand, $100 \mu \mathrm{g} / \mathrm{mL}^{-1}$ of Active human Сур A or Cyp D full-length protein dissolved in sodium acetate $10 \mathrm{mM}$ at pH 4.5 was added. In these conditions, a typical covalent binding curve was obtained. Then, the CM5 chip surface was washed with HBS buffer and no fall in the signal was observed, indicating the protein immobilization onto the sensor chip surface. Finally, ethanolamine- $\mathrm{HCl}$ was injected to deactivate the remaining active esters, remove non-covalently bound protein and avoid non-specific binding (Sanchez et al., 2015; Alfonso et al., 2014). Next, analytes were added to check the binding between them and Cyp D or Cyp A. Individual binding curves for each analytes were analyzed by determining the kinetic constant of analytes-Cyp A/D binding, namely, the observed rate constant $\left(K_{\mathrm{obs}}\right)$, the association rate constant $\left(K_{\mathrm{ass}}\right)$, the dissociation rate constant $\left(K_{\mathrm{diss}}\right)$, and the kinetic equilibrium dissociation constant $\left(K_{\mathrm{D}}\right)$. At equilibrium, by definition, $K_{\mathrm{diss}} / K_{\mathrm{ass}}=K_{\mathrm{D}}$. The pseudo-first-order association rate constants $K_{\mathrm{obs}}\left(\mathrm{s}^{-1}\right)$ were determined by using the 1:1 Langmuir association model of BiaEvaluation software (BiaCore, Uppsala, Sweden). Then a representation of $K_{\text {obs }}$ against the corresponding concentration of compound was done. These plots follow a linear correlation coefficient. From the equation of this representation, $K_{\mathrm{ass}}, \mathrm{M}^{-1} \mathrm{~s}^{-1}$, gradient of the Plot, and $K_{\text {diss }}, \mathrm{s}^{-1}$, intercept of the Plot was obtained. Within these two values, the kinetic equilibrium dissociation constant $K_{\mathrm{D}}$ for the analyte-Cyp A/D binding was obtained.

The duration of the sample injection was 2 min at $10 \mu \mathrm{L} \mathrm{min}^{-1}$ flow rate. Next, dissociation of bounded molecules in HBS-EP buffer flow was studied. The bounded drugs were removed from the chip surface before the next injection by adding $1 \mathrm{M}$ Glycine- $\mathrm{HCl}$ at $\mathrm{pH} 2.5$ for $1 \mathrm{~min}$. The association phase was used to quantify the compound-Cyp A/D interactions.

\subsection{Interleukin 2 release}

Human T lymphocytes at the concentration of $1 \times 10^{6}$ cells $\mathrm{mL}^{-1}$ were plated in 24 well plates and pre-treated for $2 \mathrm{~h}$ with autumnalamide $(10 \mu \mathrm{M})$. Then, cells were stimulated with Concanavalin $\mathrm{A}$ (Con A) at $50 \mu \mathrm{g} / \mathrm{mL}$ for $48 \mathrm{~h}$ to induce IL-2 release. The amount of IL-2 released to the culture medium was evaluated using a Human IL-2 ELISA kit.

\subsection{Calcineurin phosphatase activity assay}

Calcineurin phosphatase activity was used as a measure of Cyp A activity by means of a calcineurin Phosphatase Assay Kit (Enzo Life Sciences, Inc., Farmingdale, NY). This is a complete colorimetric assay kit to measure calcineurin phosphatase activity. The Cyp-Adrug complex was allowed to form for $1 \mathrm{~h}$ at room temperature. $1 \mathrm{nM}$ of Cyp A and different concentrations of drugs were employed dissolved in deionised water. After $1 \mathrm{~h}$, recombinant calmodulin $(0.25 \mu \mathrm{M})$ and recombinant calcineurin (40 units per well) were added to the complex formed between Cyp A and Autumnalamide or CsA. The complex was incubated for $30 \mathrm{~min}$. Next; RII phosphopeptide substrate was added at a final concentration of $0.15 \mathrm{mM}$ allowing the development of the reaction for $1 \mathrm{~h}$ at room temperature. Then $100 \mu \mathrm{L}$ of development reagent was added and incubated for $20 \mathrm{~min}$ at room temperature. Finally, the $A_{620}$ of the 96 -well plate samples was measured using Multi-Mode Microplate Reader Synergy ${ }^{\text {TM }} 4$ equipment from Biotek (Winooski, VT, USA).

\subsection{Western blotting}

Cells were incubated first with autumnalamide or CsA for $2 \mathrm{~h}$ after which Con A $(50 \mu \mathrm{g} / \mathrm{mL})$ was added for $48 \mathrm{~h}$. After incubation, $\mathrm{T}$ cells were centrifuged and washed twice with ice-cold saline solution (Umbreit) at $1500 \mathrm{rpm}, 5 \mathrm{~min}$ and $4{ }^{\circ} \mathrm{C}$. Then, the pellet was resuspended in $50 \mu \mathrm{L}$ of hypotonic lysis buffer solution to extract cytosolic proteins for $15 \mathrm{~min}$ with the following composition mM: 20 Tris- $\mathrm{HCl}, 10 \mathrm{NaCl}$ and $3 \mathrm{MgCl}_{2}$, $10 \mathrm{X}$ phosphatase inhibitors and $7 \mathrm{X}$ protease inhibitor. Cells were pelleted at $3000 \mathrm{rpm}, 10 \mathrm{~min}$ at $4{ }^{\circ} \mathrm{C}$ to remove the cytosolic protein fraction. The supernatant was collected and the pellet obtained was resuspended in $30 \mu \mathrm{L}$ of nuclear lysis buffer composed by: $100 \mathrm{mM}$ Tris, $2 \mathrm{mM} \mathrm{NaVO}_{4}, 10 \mathrm{mM} \mathrm{NaCl}, 1$ mM EDTA, 1 mM EGTA, 1 mM NaF, $20 \mathrm{mM} \mathrm{Na}_{4} \mathrm{P}_{2} \mathrm{O}_{7}, 1 \%$ Triton-X-100, 10\% Glycerol, $0,1 \%$ SDS and $0,5 \%$ Deoxychocolate Sodium containing $1 \mathrm{mM}$ PMSF and 10X protease inhibitor cocktail for $30 \mathrm{~min}$ vortexing every $10 \mathrm{~min}$. Samples were then centrifuged at $14000 \mathrm{~g}$ at $4{ }^{\circ} \mathrm{C}$ for $30 \mathrm{~min}$. The supernatants of interest were collected as protein nuclear fraction. The determination of protein concentration was done using Direct Detect (Millipore) using bovine serum albumin (BSA) as standard protein. 

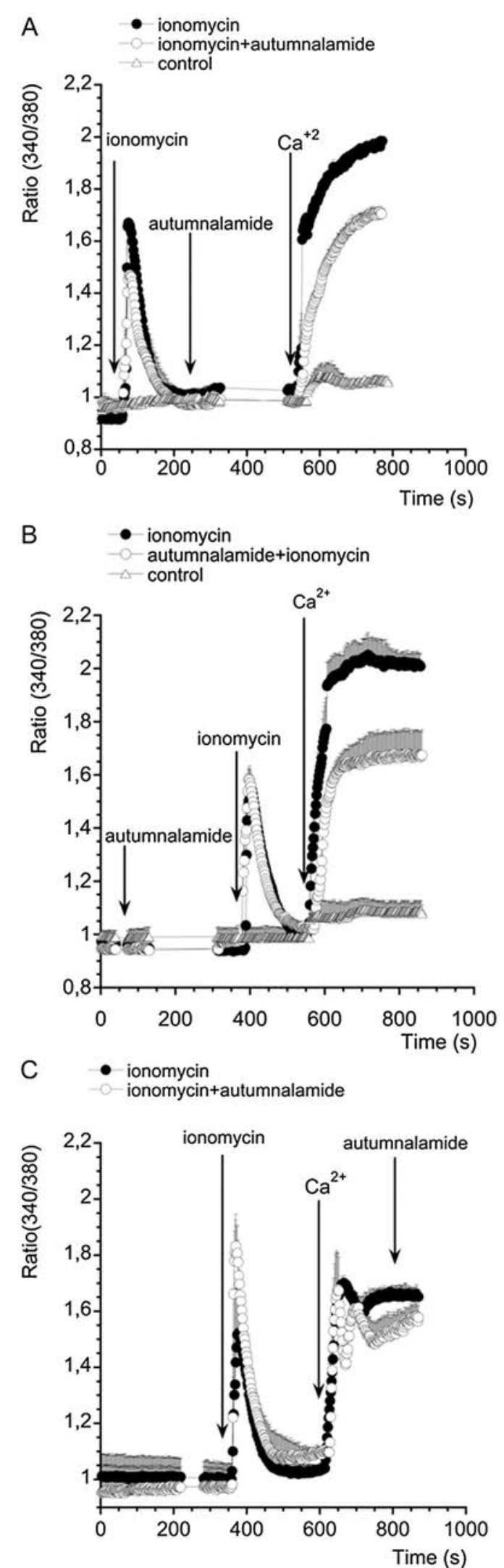

Fig. 2. Effects of autumnalamide and ionomycin cytosolic $\mathrm{Ca}^{2+}$ profile in $\mathrm{SH}-\mathrm{SY} 5 \mathrm{Y}$ neuroblastoma cells. A. First arrow indicates the addition of $2 \mu \mathrm{M}$ ionomycin. Second arrow shows addition of $10 \mu \mathrm{M}$ of autumnalamide. The third arrow indicates the addition of $\mathrm{Ca}^{2+} 1 \mathrm{mM}$ to the bath solution B. Cytosolic $\mathrm{Ca}^{2+}$ profile in cells first pre-incubated with $10 \mu \mathrm{M}$ autumnalamide (first arrow) followed
Samples of cell lysates containing $10 \mu \mathrm{g}$ of nuclear fraction of total protein were used for electrophoresis. Samples for electrophoresis were dissolved in a 15-20\% polyacrylmide gel and blotted to PVDF membrane by reduced SDS-PAGE. To determine the protein size and also to monitor the progress of the electrophoresis run, Precision Plus Protein Standards Kaleidoscope molecular weight marker was used. Then, membranes were blocked with 0,5\% BSA in washing buffer (PBS $+0.1 \%$ Tween) and incubated 10 min with primary anti-NFATc1 (1:1000). After three washes with washing buffer (PBS + 0.1\% Tween 20), membranes were incubated with secondary anti-Mouse IgG conjugated with horseradish peroxidase. The immunoreactive bands were detected using the Supersignal West Pico or Supersignal West Femto Maximum Sensitivity Substrate (Pierce) and the Diversity GeneSnap software (Syngene). NFATc1 signal was normalized using Lamin B1 (1:1000).

\subsection{Statistical analysis}

All experiments were carried out by duplicate a minimum of three times. Results were analyzed by using one-way analysis of variance ANOVA with Dunnett's post hoc analysis. p values $<0.05$ were considered statistically significant. All results were expressed as the mean \pm SEM of 3 or more experiments.

\section{Results}

Considering the results obtained in a previous work, autumnalamide was able to completely inhibit SOC channels by its effect over mitochondrion (Audoin et al., 2014). Therefore, several additional calcium $\left(\mathrm{Ca}^{2+}\right)$ experiments were carried out in order to clarify the effect of autumnalamide on $\mathrm{Ca}^{2+}$ fluxes different from SOC. To do this, the effect of autumnalamide on ionomycin $\mathrm{Ca}^{2+}$ fluxes was studied. Ionomycin is a $\mathrm{Ca}^{2+}$ ionophore that induces intracellular pools depletion and allows $\mathrm{Ca}^{2+}$ entrance from the extracellular medium (Morgan and Jacob, 1994). Thus, autumnalamide was added in a $\mathrm{Ca}^{2+}$-free medium after ionomycin pools depletion, and a significant cytosolic $\mathrm{Ca}^{2+}$ influx reduction was observed after ion addition (Fig. 2A). In the same way, when the compound was incubated in a $\mathrm{Ca}^{2+}$-free medium before ionomycin addition, no modification on intracellular stores was observed neither on ionomycin-sensitive pools depletion. Nevertheless, once $\mathrm{Ca}^{2+}$ ion was restored, a significant ion-influx inhibition was obtained comparing to ionomycin (Fig. 2B). Moreover, autumnalamide did not inhibit the ion entrance once the influx is activated (Fig. 2C). Thus, autumnalamide did not affect intracellular pools modulated by ionomycin; nevertheless cytosolic $\mathrm{Ca}^{2+}$ entrance was reduced a $30 \%$ when the incubation with autumnalamide was done after or before ionomycin-sensitive pools depletion. Therefore, as it was reported, the compound inhibits SOC entrance.

In order to confirm if autumnalamide inhibits other $\mathrm{Ca}^{2+}$ influx different from SOC, flufenamic acid (FFA) was employed. FFA is a non-steroidal drug that acts inducing $\mathrm{Ca}^{2+}$ release from the mitochondrion in a $\mathrm{Ca}^{2+}$ free medium (Jiang et al., 2012; Damsker et al., 2009; Zeng et al., 2012). Thus, when FFA was incubated in the absence of $\mathrm{Ca}^{2+}$, a significant $\mathrm{Ca}^{2+}$ release from internal stores was induced. In addition, when $\mathrm{Ca}^{2+}$ was added to the medium an ion influx was observed (Fig. 3A). Nevertheless, when autumnalamide was incubated before the FFA addition, the $\mathrm{Ca}^{2+}$ release from mitochondrion was significantly inhibited, besides after addition of $\mathrm{Ca}^{2+}$ the ion reached similar levels than FFA (Fig. 3A). Therefore, the

by ionomycin $2 \mu \mathrm{M}$ (second arrow). The third arrow indicates $1 \mathrm{mM}$ of $\mathrm{Ca}^{2+}$ addition to the bath solution. $\mathrm{C}$. The first arrow shows the ionomycin addition. The second arrow shows the $\mathrm{Ca}^{2+}$ addition to the medium and the third the addition of $10 \mu \mathrm{M}$ of autumnalamide. The experiments were performed in duplicate. The results of each replica are mean of 20 cells. Mean \pm SEM of three independent experiments. 

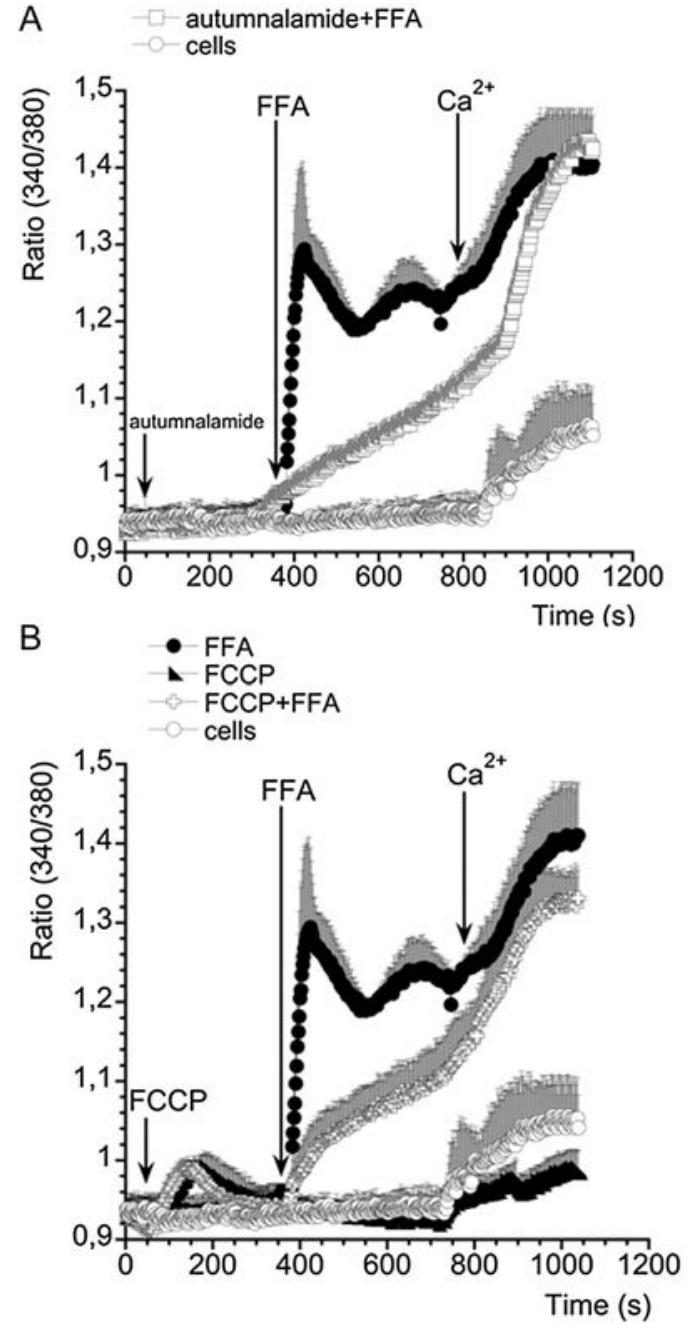

Fig. 3. Effect of FCCP or autumnalamide and FFA on cytosolic $\mathrm{Ca}^{2+}$ profile in $\mathrm{SH}-$ SY5Y neuroblastoma cells. A. First arrow indicates autumnalamide addition and the second arrow the FFA addition. The third arrow indicates the addition of $\mathrm{Ca}^{2+}$. B. The FCCP addition to the medium (first arrow) prior to FFA addition (second arrow). The third arrow indicates the addition of the ion to the $\mathrm{Ca}^{2+}$-free bathed solution. The experiments were performed in duplicate. The results of each replica are mean of 20 cells. Mean \pm SEM of three independent experiments.

compound does not affect mitochondrial $\mathrm{Ca}^{2+}$ influx, however the release of the ion from this organelle was largely reduced. In order to know the effect of other mitochondrial uncouplers on FFA, FCCP was employed (Ma et al., 2012). As shown in Fig. 3B, FCCP produced a small increase in $\mathrm{Ca}^{2+}$ levels; and the following addition of FFA did not induce a $\mathrm{Ca}^{2+}$ release. Thus, after the ion addition to the bath solution, a similar $\mathrm{Ca}^{2+}$ influx as FFA control was observed. Therefore, as in the case of autumnalamide, the prior incubation with FCCP inhibited the $\mathrm{Ca}^{2+}$ release induced by FFA without affecting the next $\mathrm{Ca}^{2+}$ influx. Summarizing the results described above, both, FCCP and autumnalamide were able to decrease the release of $\mathrm{Ca}^{2+}$ from mitochondrion induced by FFA; nevertheless the cytosolic $\mathrm{Ca}^{2+}$ entrance was not blocked. In addition, autumnalamide inhibited cytosolic $\mathrm{Ca}^{2+}$ influx induced by the ionophore while ionomycin-sensitive intracellular pools were not modified. Therefore, autumnalamide targeted mitochondrion without inducing $\mathrm{Ca}^{2+}$ release from this organelle but inhibiting SOC influx.

In order to explain the effect of autumnalamide on $\mathrm{Ca}^{2+}$ handling and since in a previous work it was observed the effect of autumnalamide inhibiting $\mathrm{Ca}^{2+}$ influx, which was reverted by CsA (Audoin et al., 2014), the structures that this drug targets were studied. With this purpose, the highly sensitive biosensor Biacore $\mathrm{X}$ was used to determine the binding between mitochondrial Cyp D, used as ligand, attached to the sensor surface and using autumnalamide as ligate. First, CsA was used as control of binding for the immobilized Cyp D. As Fig. 4A shows, when different concentrations of CsA (5, 10,20 and $40 \mu \mathrm{M}$ ) were added over the immobilized Cyp D, typical association curves profiles were obtained. In the presence of $5 \mu \mathrm{M}$ CsA the signal was $10.05 \mathrm{RU}$, while in the presence of $40 \mu \mathrm{M}$ of CsA the response reached 31.8 RU. Individual binding curves from Fig. 4 A were analyzed as described in the material and methods section. $K_{\mathrm{obs}}$ for each concentration of CsA were obtained. When $K_{\mathrm{obs}}$ were represented against each CsA concentration, (Fig. 4B), a linear regression with a correlation coefficient of $r=0.97985$ for Cyp $D$ was obtained. From this representation, $\mathrm{K}_{\mathrm{ass}}, \mathrm{M}^{-1} \mathrm{~s}^{-1}$, slope, $\mathrm{K}_{\text {diss }}$, $\mathrm{s}^{-1}$, and Y-intercept, were obtained. Within these two values, the kinetic equilibrium dissociation constant $K_{\mathrm{D}}$ (Y-intercept/slope) for the CsA-Cyp D association was obtained. The value of this constant was $4.5 \times 10^{-6} \pm 3.05 \times 10^{-6} \mathrm{M}$ for the CsA-Cyp D binding assay (Fig. 4B). After setting up these conditions the binding of Cyp D and autumnalamide was next studied. In this case, different concentrations of autumnalamide $(30,50,70$ and $100 \mu \mathrm{M})$ were dissolved in HBS-EP buffer and added onto the previously immobilized Cyp D. Thus, as Fig. 4C shows, association curves for the binding of autumnalamide with Cyp D were obtained with responses ranging from $10 \mathrm{RU}$ at the lowest autumnalamide concentration to 220 $\mathrm{RU}$ in the presence of $100 \mu \mathrm{M}$ of the compound. As in the case of CsA, the interaction between autumnalamide and Cyp D follows a pseudo-first order kinetic where $K_{\text {obs }}$ was calculated. When each $K_{\text {obs }}$ was represented against the corresponding concentration of autumnalamide from Fig. 4C, linear regression plots with a correlation coefficient of $r=0.98$, for the binding of autumnalamide to Cyp D were obtained. From these representations the kinetic equilibrium constant for the binding of autumnalamide to Cyp D was calculated. In the case of the Cyp D-autumnalamide binding, a $K_{\mathrm{D}}=1.51 \pm 1.399 \mu \mathrm{M}$ (Fig. 4D) was obtained. Due to Cyps share a common region domain and since autumnalamide showed good binding affinity for Cyp D, the effect of this compound over Cyp A, another important immunophilin, was also evaluated. Straightaway, the same procedure was followed for Cyp A immobilization over a CM5 chip as described in Material and Methods. Thus, when different concentrations of CsA were added over the immobilized Cyp A, typical association curves were obtained. In the presence of $5 \mu \mathrm{M}$ CsA the signal was $17.54 \mathrm{RU}$, while in the presence of $40 \mu \mathrm{M}$ of CsA the response reached 55.45 RU (Fig. 5A). In this case, a $K_{\mathrm{D}}$ for CsA-Cyp A was $6.83 \times 10^{-6} \pm 1.1 \times 10^{-6} \mu \mathrm{M}$ (Fig. $5 \mathrm{~B}$ ). In the same way, different concentrations of autumnalamide were dissolved in HBS-EP buffer and added onto the immobilized Cyp A. Thus, as Fig. 5C shows, association curves for the binding of autumnalamide with Cyp A were obtained with responses ranging from 34.11RU at the lowest concentration to 102.5 RU at the highest concentration of autumnalamide. From the association curves a $K_{\mathrm{D}}$ of $8.08 \pm 1.23 \mu \mathrm{M}$ was obtained (Fig. 5D). So far the results obtained here indicated that autumnalamide showed higher affinity for Сур D than CsA and also a good affinity for Cyp A, although slightly smaller than that of CsA.

Hence, autumnalamide showed Cyp A binding, and also acts by inhibiting SOC influx; both targets are related with the modulation of interleukins (ILs) (Sweeney et al., 2009; Djuric et al., 2000), we then tested the effect of autumnalamide on IL-2 production in human T lymphocytes. In previous work the effect of autumnalamide in SH-SY5Y cell viability was checked for $1 \mathrm{~h}$, and the compound produced a $42 \%$ of decrease in cell viability at the concentration of $25 \mu \mathrm{M}$ (the highest concentration tested) (Audoin et al., 2014). In order to develop experiments with prolonged exposure times and in different cellular model, it was necessary to check cell toxicity of autumnalamide. To do this, different concentrations 


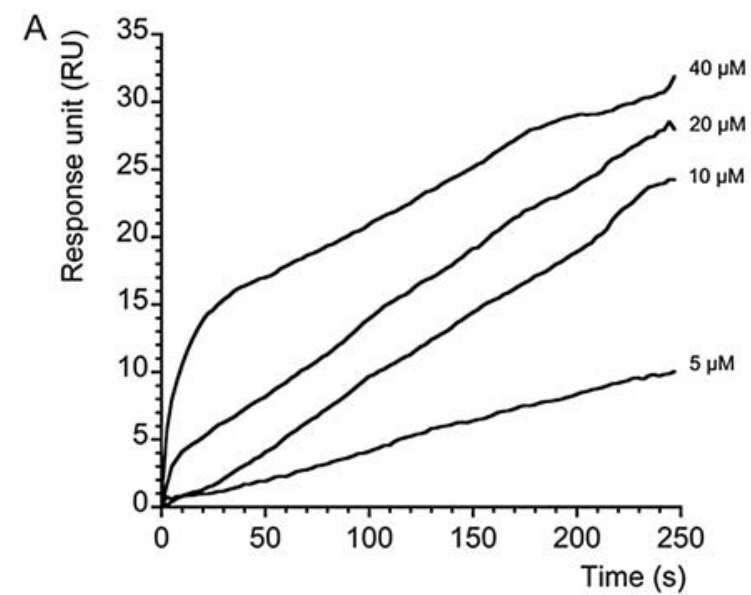

B
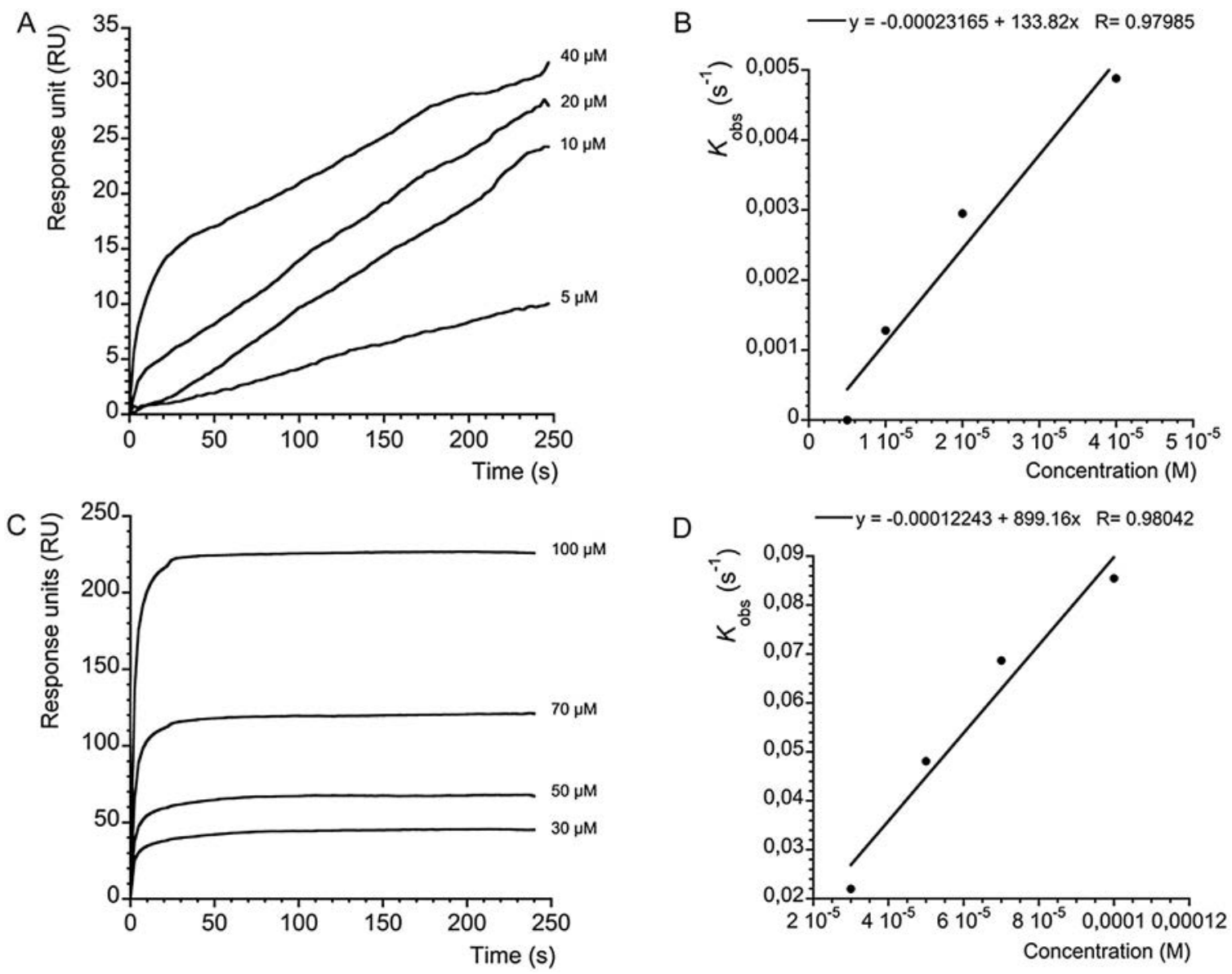

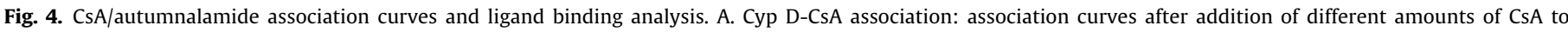

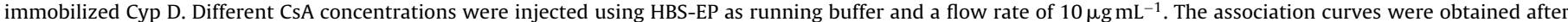

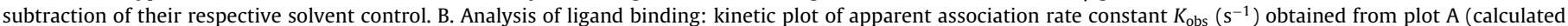

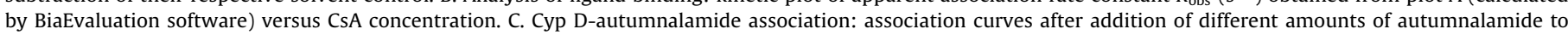

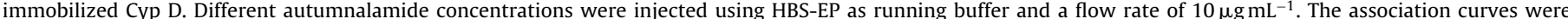

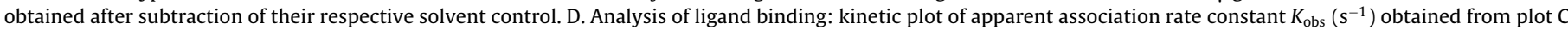
(calculated by BiaEvaluation software) versus autumnalamide concentration. Representative experiment of $n=3$.

ranges of autumnalamide were tested for 24 and $48 \mathrm{~h}$ in human T lymphocytes. As Fig. 6 shows, the concentrations tested for the two exposure times did not produced any changes on cell viability. Once again, the concentration of $10 \mu \mathrm{M}$ was selected to develop the current experiments at $48 \mathrm{~h}$.

To develop IL-2 experiments, a control of human T lymphocytes was treated with Con A alone, to induce IL-2 release, or in combination with autumnalamide. After $48 \mathrm{~h}$ of incubation, IL-2 release in the culture medium was measured. As Fig. 7 shows, the stimulation of human $\mathrm{T}$ lymphocytes with Con A for $48 \mathrm{~h}$ efficiently induces IL-2 production comparing with non-stimulated control cells from $47.72 \pm 1.58 \mathrm{pg} \mathrm{mL}^{-1}$ to $742,77 \pm 152.23 \mathrm{pg} \mathrm{mL}^{-1}$ respectively $(\mathrm{p} \leq 0.001)$. In this conditions, when $\mathrm{T}$ lymphocytes were pre-incubated for $2 \mathrm{~h}$ with $10 \mu \mathrm{M}$ autumnalamide, before stimulation with ConA for $48 \mathrm{~h}$, a reduction from $742,77 \pm 152.23 \mathrm{pg} \mathrm{mL}^{-1}$ to $111.61 \pm 3.4 \mathrm{pg} \mathrm{mL}^{-1}(\mathrm{p} \leq 0.01)$. The well-known IL-2 inhibitor CsA was used as positive control of IL-2 inhibition. Thus, when cells were pre-incubated with CsA $0.2 \mu \mathrm{M}$ for $2 \mathrm{~h}$ before Con A stimulation, IL-2 production was significantly reduced to control values $146.25 \pm 111.34 \mathrm{pg} \mathrm{mL}^{-1}(\mathrm{p} \leq 0.01)$. From these results we conclude that both compounds suppressed IL-2 release from human activated $\mathrm{T}$ lymphocytes with a similar efficacy.

In view of these results two additional experiments were performed to evaluate the mechanisms underlying the effects of autumnalamide in IL-2 blockade. Some compounds, as in the case of CsA, act docking calcineurin phosphatase activity over NFATc1 and the next IL-2 induction due to the binary complex formed with Cyp A (Randak et al., 1990). Therefore, in view of the binding of autumnalamide to Cyp A, the ability of autumnalamide to inhibit calcineurin phosphatase activity was next compared. In this case, a compound concentration close to the calculated $K_{\mathrm{D}}$ was used. As Fig. 8 shows, when Cyp A was incubated in the presence of $6 \mu \mathrm{M}$ CsA a significant reduction in calcineurin phosphatase activity of $28.33 \pm 3.07 \%(p \leq 0.01)$ was observed. In the same way, in the presence of $10 \mu \mathrm{M}$ of autumnalamide a significant $18.87 \pm 2.21 \%$ $(\mathrm{p} \leq 0.001)$ reduction was observed over calcineurin phosphatase activity.

It is known that $\mathrm{T}$ lymphocyte stimulation with Con $\mathrm{A}$ induce a cytosolic $\mathrm{Ca}^{2+}$ increase (Smith-Garvin et al., 2009). As a consequence, Cyp A forms a complex with calcineurin that binds to and dephosphorylates cytosolic NFATc1. The dephosphorylation of the nuclear factor leads to the translocation to the nucleus. The increase in the nuclear expression of NFATc1 in a transcriptionally active form leads to the increase of IL-2 production (Liu, 2009; Xiong et al., 2013). Therefore, the nuclear expression of NFATc1 in activated human peripheral $\mathrm{T}$ lymphocytes in the presence of autumnalamide was next checked and compared with the effect of CsA in the same condition. Representative western blot bands for these results are shown in Fig. 9A. As shown in Fig. 9B, the quantification of western blot band intensities in each condition showed 


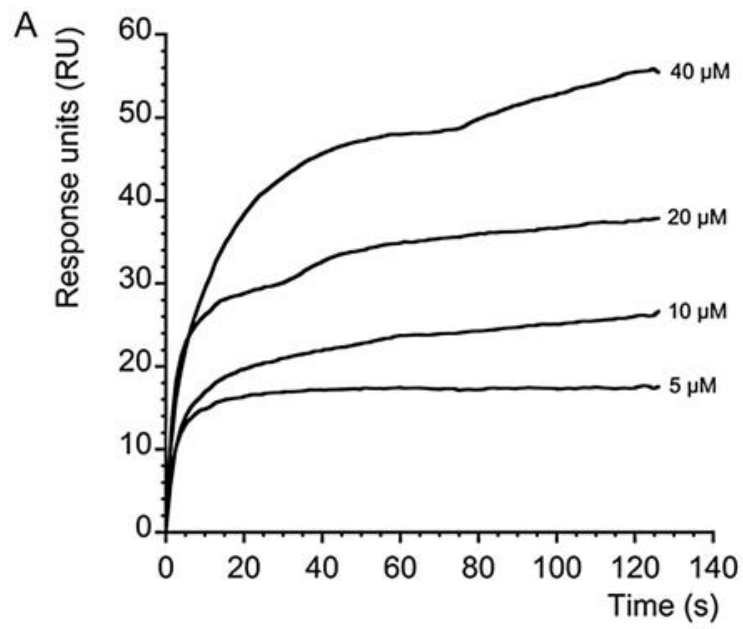

B
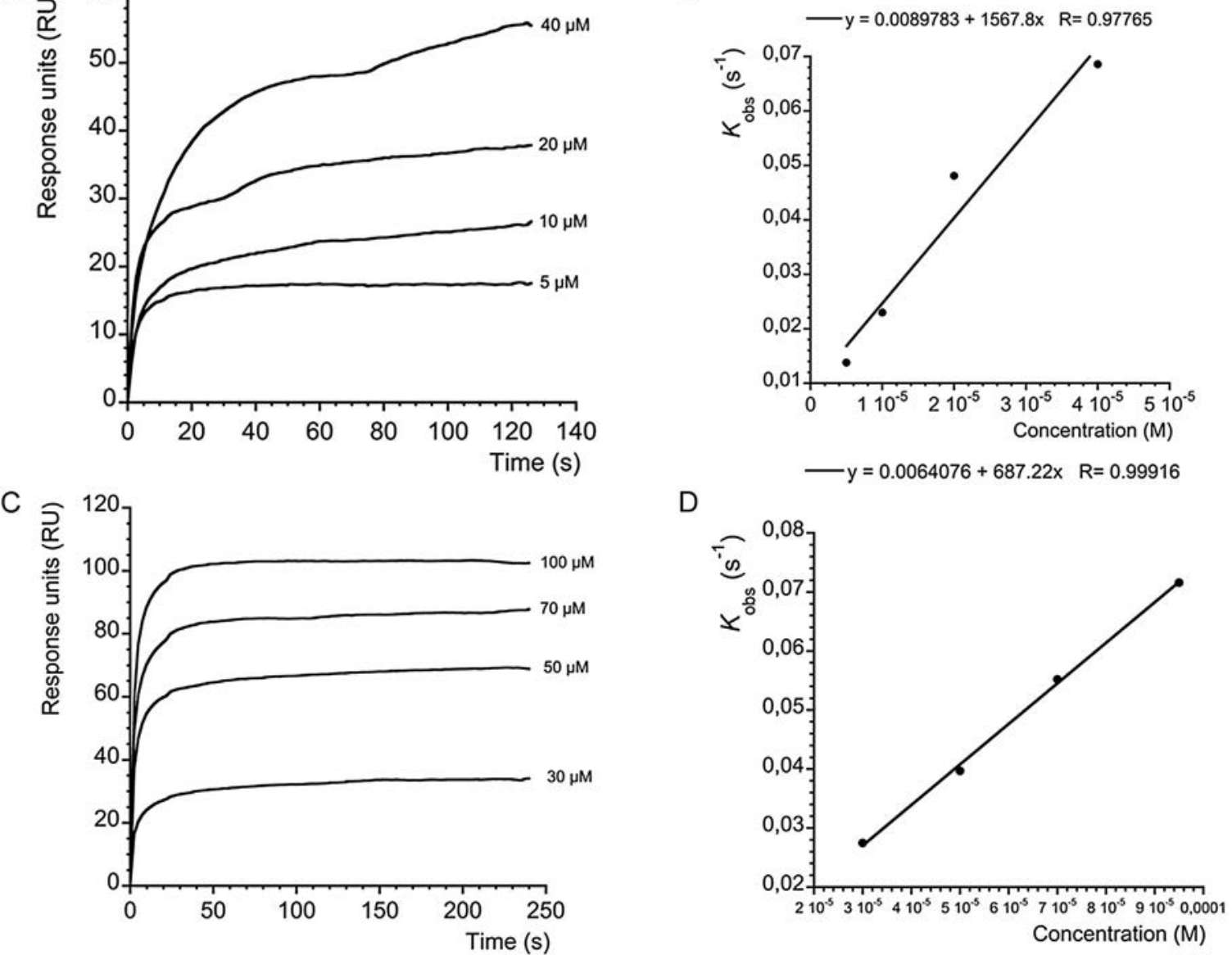

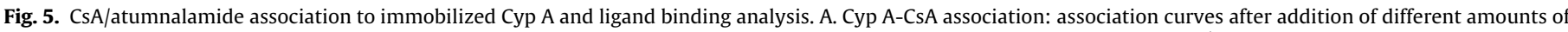

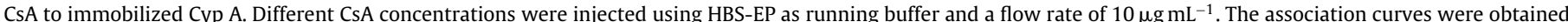

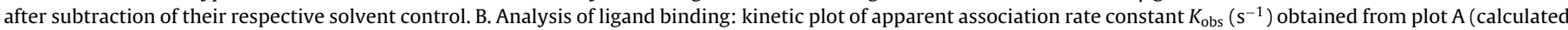

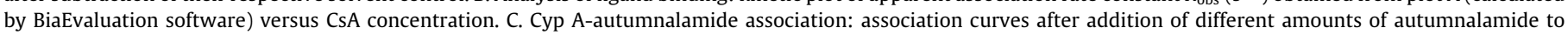

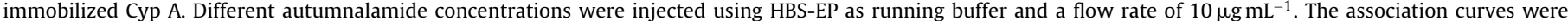

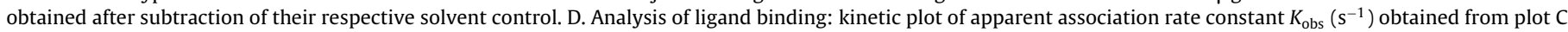
(calculated by BiaEvaluation software) versus autumnalamide concentration. Representative experiment of $n=3$.

that when cells were stimulated with Con A for $48 \mathrm{~h}$ nuclear band intensity of NFATc1 exhibited a $67.21 \pm 0.12 \%(\mathrm{p} \leq 0.01)$ increase comparing with $\mathrm{T}$ cells in resting conditions. Pre-incubation of the cells with CsA before activation decreased NFATc1 band intensity close to control values, in agreement with previously reported results (Ishikawa et al., 2003). However, autumnalamide did not significantly reduce the increase in nuclear NFATc1 in activated human T lymphocytes that reach higher levels than Con A treated cells.

Altogether, the results presented here indicate that, autumnalamide does not modify ionomycin-sensitive intracellular $\mathrm{Ca}^{2+}$ pools, besides confirm that the compound inhibits the SOC channels. Moreover, it binds to mitochondrion Cyp D, presents binding affinity for Cyp A and inhibits calcineurin and human IL-2 production in activated T lymphocytes but, unlike CsA, it lacks of an inhibitory effect over NFATc1.

\section{Discussion}

The structure of the prenylated cyclic peptide named autumnalamide was recently identified and the same paper reported the only available data on the compound, indicating that autumnalamide alters mitochondrial membrane potential in neuroblastoma cells and also induces the MPTP opening (Audoin et al.,
2014). The opening of this structure can be induced by different substances that do not necessarily target the proteins that form the mPTP structure (Tornero et al., 2002). There are many molecules from the own organism that act as inducers of $\mathrm{MPTP}$, such as $\beta$ Amyloid $(\beta A)$ protein, as well as molecules with natural origin like mastoparan from the venom of Vespula lewisii; honokiol from Magnolia spp. or molecules from synthetic sources like MT-21. Nevertheless, almost no molecule acts targeting directly Cyp D, both for blocking or inducing the formation of MPTP. In the case of $\beta A$ protein, it induces the production of Reactive Oxygen Species (ROS), mastoparan forms channels in the mitochondria and MT-21 directly induces the release of cytochrome $\mathrm{c}$ from mitochondria. All these factors lead to the opening of MPTP (Watabe et al., 2000; Ding and Nam Ong, 2003; Du and Yan, 2010; Arora et al., 2012). Thus, with the exception of honokiol, none of these compounds induces the MPTP opening directly by binding to a specific component of the multiproteic complex, as we observed with autumnalamide in the present paper. On the other hand, $\mathrm{Ca}^{2+}$ experiments reveal that autumnalamide neither modify ionomycin-sensitive intracellular $\mathrm{Ca}^{2+}$ pools, nor the ionomycin $\mathrm{Ca}^{2+}$ entrance through SOC channels once the influx is activated. Nevertheless, the $\mathrm{Ca}^{2+}$ profiles obtained from the present study show that the FFA-induced $\mathrm{Ca}^{2+}$ release in SH-SY5Y is inhibited by pre-treatment with FCCP, which collapse the mitochondrial membrane potential that normally drives 


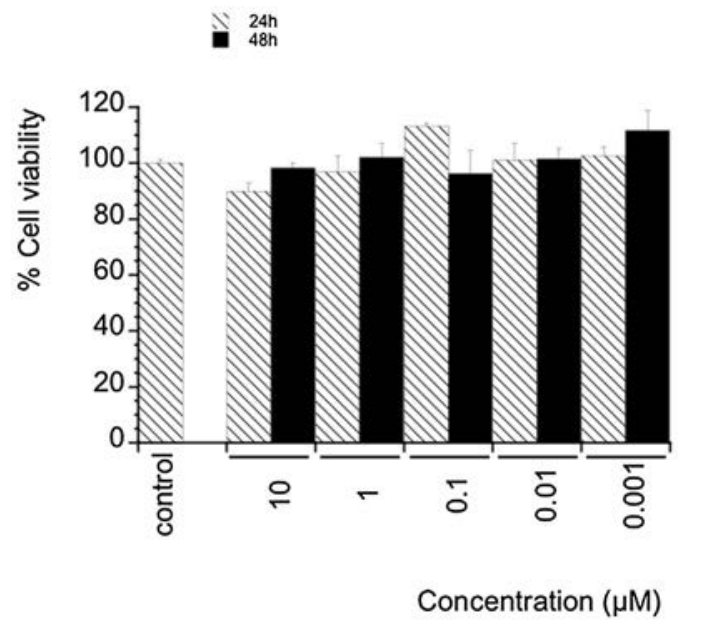

Fig. 6. Effect of autumnalamide over T lymphocytes cell viability. T lymphocytes cells were incubated for 24 and $48 \mathrm{~h}$ with autumnalamide at the concentration range from $1 \mathrm{nM}$ to $10 \mu \mathrm{M}$. Bar columns represent the different concentrations for each times. Effect on cell viability tested by MTT test. Data are mean \pm SEM of 3 independent experiments. Data are mean \pm SEM of 3 independent experiments.

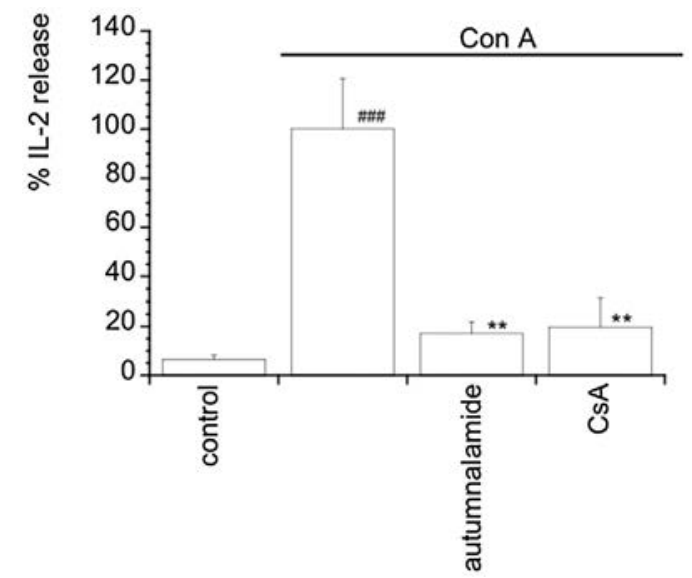

Fig. 7. Effect of CsA or autumnalamide on IL-2 production in human T lymphocytes stimulated with Con A. Human T lymphocytes were pre-treated for two hours with CsA $(0.2 \mu \mathrm{M})$ or autumnalamide $(10 \mu \mathrm{M})$ and then with Con A $(50 \mu \mathrm{g} \mathrm{mL}-1)$ for $48 \mathrm{~h}$. Mean \pm SEM of three experiments. All values are shown in percentage to the Con A treated cells. ${ }^{* *}$ Significant differences between autumnalamide or CsA treated cells with respect to cells treated with Con A $(p<0.01)$. \# Significant differences between Con A treated cells and control $(p<0.001)$. Mean \pm SEM of 3 independent experiments.

the $\mathrm{Ca}^{2+}$ into the mitochondrion (Collins et al., 2000). The effect of autumnalamide over FFA may be achieved through either a protonophore-like effect, similar to FCCP, or the induction of the mPTP, as previously described (Audoin et al., 2014). Thus, in the case of FCCP in SH-SY5Y cells, the uncoupling of the mitochondrial transport chain produced in mitochondria, substantially inhibits $\mathrm{Ca}^{2+}$ release induced by FFA probably because both FCCP and FFA act by disrupting mitochondrial membrane potential, and one drug blocks the effect of the other (Chi et al., 2011). Moreover, CsA abolished the effect of autumnalamide efficiently in comparison with FCCP on SOC $\mathrm{Ca}^{2+}$ influx (Audoin et al., 2014). In accordance with these previous results and due to the effect observed over MPTP by autumnalamide, the binding of the prenylated cyclic peptide from the cyanobacterium Phormidium autumnale was tested on Cyp $D$, an essential component of the MPTP. Biosensor data analysis indicates that the compound binds with good affinity to mitochondrial Cyp D. Autumnalamide almost shows 3 times more affinity for mitochondrial Cyp D than CsA. Moreover, due to the findings

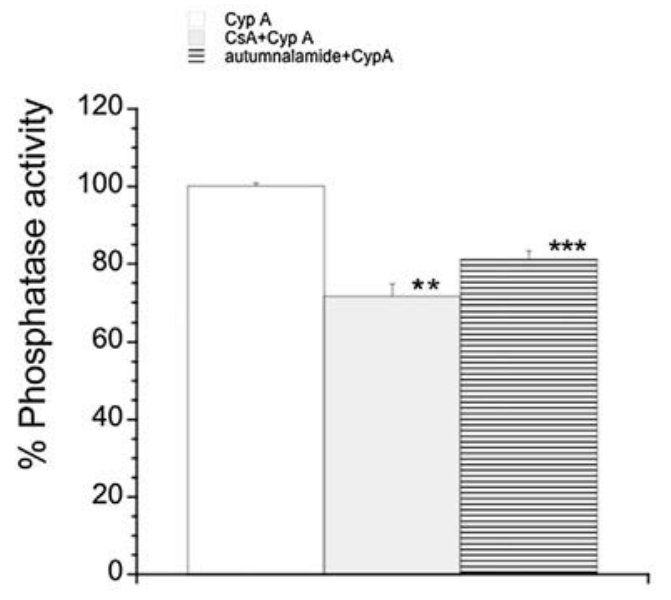

Fig. 8. Effect of autumnalamide or $\mathrm{CsA}$ on $\mathrm{Ca}^{2+} /$ calmodulin-dependent on Phosphatase Activity of Calcineurin. Phosphatase activity of calcineurin determined after pre-incubation with Cyp A or Cyp A+CsA $(6 \mu \mathrm{M}) /$ autumnalamide $(10 \mu \mathrm{M})$. All values are shown in percentage with respect to Cyp A control. **Significant differences between Cyp A control and Cyp A+CsA $(p \leq 0.01)$. ${ }^{* * *}$ Significant differences between Cyp A control and Cyp A+autumnalamide $(p \leq 0.001)$. Data are mean \pm SEM of 3 independent experiments.
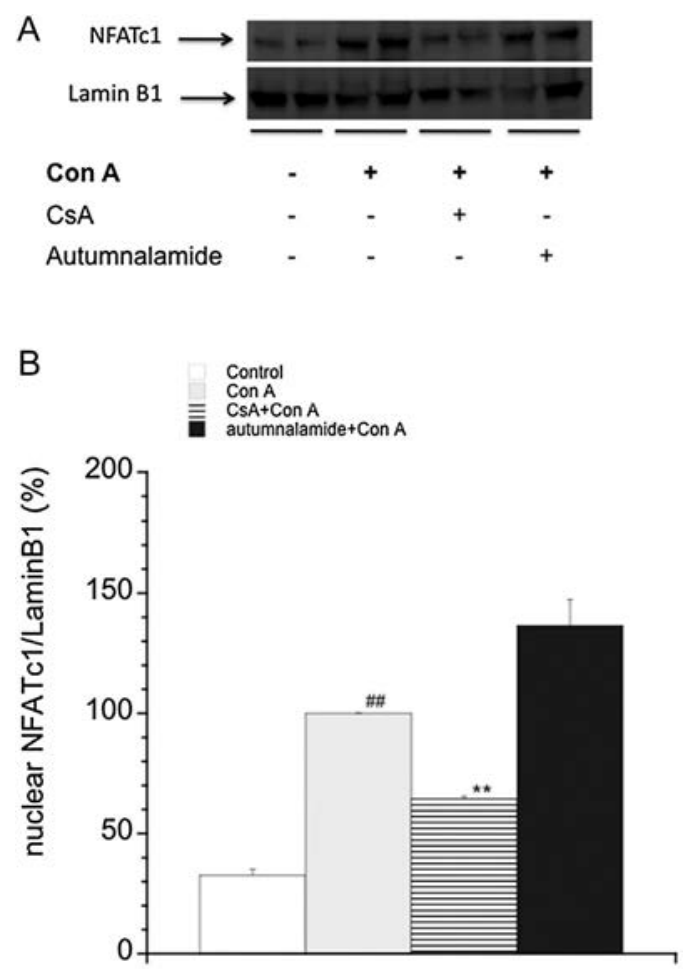

Fig. 9. Effect of CSA or autumnalamide over NFATc1 nuclear levels in human T lymphocytes activated with Con A. A. NFATc1 levels were studied as nuclear fraction after $48 \mathrm{~h}$ incubation with compounds. Human T lymphocytes were pre-treated for $2 \mathrm{~h}$ with $\operatorname{CsA}(0.2 \mu \mathrm{M})$ or autumnalamide $(10 \mu \mathrm{M})$ and afterward incubated with Con A $\left(50 \mu \mathrm{g} \mathrm{mL}^{-1}\right)$ for $48 \mathrm{~h}$. A. Representative image of one experiment. B. Mean of the ratio of the nuclear NFATc1/lamin B1 band intensity. All results are presented as the percentage of NFATc1 in the nucleus. \#\#Significant differences with respect to control cells $(\mathrm{p} \leq 0.01)$. ${ }^{* *}$ Significant differences with respect to Con A treated cells $(p<0.01)$. Data are mean \pm SEM of three experiments.

observed by SPR and taking into account the results observed on mPTP besides the uncoupling effect (Audoin et al., 2014), this effect could be related with the interaction between autumnalamide and mitochondrial Cyp D in a more specific way than in the case of FCCP or FFA that is produced mainly by the disruption of membrane potential. Cyps share a common domain; therefore compounds that 
bind to one of this protein family usually show binding affinity for other Cyps as CsA display (Kumari et al., 2013). Thus, autumnalamide also shows, as CsA, Cyp A binding affinity. This cytosolic protein plays a central pathway of many physiological and pathological processes in the cells such as inflammation, cardiovascular diseases, immunomodulation or sepsis among others (Nigro et al., 2013). In the case of CsA, once the complex between Cyp A- CsA is formed, calcineurin phosphatase activity is blocked and the translocation of NFAT to the nucleus is avoided, inhibiting the transcription activity over genes that encodes for IL-2 (Fruman et al., 1992). Autumnalamide reduces calcineurin phosphatase activity, while NFAT was not reduced after the binding to Cyp A, nevertheless, autumnalamide, as CsA, reduces IL-2 production in T lymphocytes. While CsA exerts its effect through the docking of calcineurin (Naesens et al., 2009), the inhibition of IL-2 produced by autumnalamide probably occurs partially by a calcineurin-independent pathway since the nuclear entry of the NFATc 1 is closely linked to its dephosphorilation and the nuclear levels of this transcription factor are not blocked after autumnalamide treatment. Molecules that inhibit CRAC channels are also expected to reduce IL-2 production (Sweeney et al., 2009; Djuric et al., 2000). As FFA or BTP2, two compounds that modulate SOC channels, act by reducing the production of this IL in white blood cells, being $\mathrm{Ca}^{2+}$ an essential signal for its production (Kankaanranta et al., 1996; Cardenas and Heitman, 1995). In the case of autumnalamide, the indirect blockade produced on SOC channels, the main $\mathrm{Ca}^{2+}$ entrance in $\mathrm{T}$ cells, due to the effects that produce in mitochondrion, could explain the effect over IL-2 inhibition, although it does not block NFAT translocation. Then, other transcription factors or mitogen-activated protein kinases (MAPK) could be related with the modulation of interleukins (ILs) by autumnalamide where the restriction of cytosolic $\mathrm{Ca}^{2+}$ induced by the compound may be essential (Audoin et al., 2014; Cardenas and Heitman, 1995; Kar et al., 2011). On the other hand, autumnalamide can be a useful tool to study molecules that targeted Cyp D, other applications could be attributed to autumnalamide due to the binding to Cyp A. This effort mainly led to the development of compounds with immunosuppressive or antiinflammatory effects.

As a conclusion, we have a drug that has good affinity for two important immunophilins engaged in many diseases and produces an effective blockade on IL-2 production and low toxicity. Due to the multi-functional properties of Сyp A and the functions where it is involved, such as protein folding, trafficking, assembly or cell signaling, autumnalamide could open a new window to improve the treatment of many diseases where Cyp A is a key player (Nigro et al., 2013). With respect to Cyp D, the fact that MPTP is a process regulated by a wide type of stimulus, it makes this multiproteic complex an ideal pharmacological target implicated in multiple processes, where autumnalamide directly binds to (Tornero et al., 2002).

\section{Conflict of interest statement}

The authors declare no conflict of interest.

\section{Acknowledgements}

The research leading to these results has received funding from the following FEDER cofounded-grants. From CDTI and Technological Funds, supported by Ministerio de Economía y Competitividad, AGL2012-40185-CO2-01, AGL2014-58210-R, and Consellería de Cultura, Educación e Ordenación Universitaria, GRC2013-016, and through Axencia Galega de Innovación, Spain, ITC-20133020 SINTOX. From CDTI under ISIP Programme, Spain, IDI-20130304APTAFOOD.
From the European Union's Seventh Framework Programme managed by REA - Research Executive Agency (FP7/2007-2013) under grant agreement 312184PHARMASEA. We wish to thank the Clínica Losada Arránz, especially Ms. Paula López Arránz for providing the human blood samples for T cells purification. Jon Andoni Sánchez is supported by a fellowship from Plan Galego de Investigación e Crecemento, Xunta de Galicia, Spain.

\section{References}

Alfonso, A., Botana, M.A., Vieytes, M.R., Botana, L.M., 2001. Prolactin induces calcium influx and release from intracellular pools in human $\mathrm{T}$ lymphocytes by activation of tyrosine kinases. Cell. Signal. 13, 819.

Alfonso, A., Pazos, M.J., Fernandez-Araujo, A., Tobio, A., Alfonso, C., Vieytes, M.R., Botana, L.M., 2014. Surface plasmon resonance biosensor method for palytoxin detection based on $\mathrm{Na}+, \mathrm{K}+-\mathrm{ATP}$ ase affinity. Toxins (Basel) 6, 96.

Arora, S., Singh, S., Piazza, G.A., Contreras, C.M., Panyam, J., Singh, A.P., 2012. Honokiol: a novel natural agent for cancer prevention and therapy. Curr. Mol. Med. 12, 1244.

Audoin, C., Sanchez, J.A., Genta-Jouve, G., Alfonso, A., Rios, L., Vale, C., Thomas, O.P., Botana, L.M., 2014. Autumnalamide, a prenylated cyclic peptide from the cyanobacterium Phormidium autumnale, acts on SH-SY5Y cells at the mitochondrial level. J. Nat. Prod. 77, 2196.

Cardenas, M.E., Heitman, J., 1995. Role of calcium in T-lymphocyte activation. Adv. Second Messenger Phosphoprotein Res. 30, 281.

Chi, Y., Li, K., Yan, Q., Koizumi, S., Shi, L., Takahashi, S., Zhu, Y., Matsue, H., Takeda, M., Kitamura, M., Yao, J., 2011. Nonsteroidal anti-inflammatory drug flufenamic acid is a potent activator of AMP-activated protein kinase. J. Pharmacol. Exp. Ther. 339, 257.

R.C.T. Coates, E. Trentacoste, W.H. Gerwick, (2013), Bioactive and Novel Chemicals from Microalgae, Oxford, UK.

Collins, T.J., Lipp, P., Berridge, M.J., Li, W., Bootman, M.D., 2000. Inositol 1,4,5-trisphosphate-induced Ca2+ release is inhibited by mitochondrial depolarization. Biochem. J 347, 593.

Damsker, J.M., Okwumabua, I., Pushkarsky, T., Arora, K., Bukrinsky, M.I., Constant S.L., 2009. Targeting the chemotactic function of CD147 reduces collagen-induced arthritis. Immunology 126, 55.

Davis, T.L., Walker, J.R., Campagna-Slater, V., Finerty, PJ., Paramanathan, R., Bernstein, G., MacKenzie, F., Tempel, W., Ouyang, H., Lee, W.H., Eisenmesser, E.Z., Dhe-Paganon, S., 2010. Structural and biochemical characterization of the human cyclophilin family of peptidyl-prolyl isomerases. PLoS Biol. 8, e1000439.

Ding, W.X., Nam Ong, C., 2003. Role of oxidative stress and mitochondrial changes in cyanobacteria-induced apoptosis and hepatotoxicity. FEMS Microbiol. Lett. 220,1

Djuric, S.W., BaMaung, N.Y., Basha, A., Liu, H., Luly, J.R., Madar, D.J., Sciotti, R.J., Tu, N.P., Wagenaar, F.L., Wiedeman, P.E., Zhou, X., Ballaron, S., Bauch, J., Chen, Y.W., Chiou, X.G., Fey, T., Gauvin, D., Gubbins, E., Hsieh, G.C., Marsh, K.C., Mollison, K.W., Pong, M., Shaughnessy, T.K., Sheets, M.P., Smith, M., Trevillyan, J.M., Warrior, U., Wegner, C.D., Carter, G.W., 2000.

3,5-Bis(trifluoromethyl)pyrazoles: a novel class of NFAT transcription factor regulator. J. Med. Chem, 43, 2975.

Du, H., Yan, S.S., 2010. Mitochondrial permeability transition pore in Alzheimer's disease: cyclophilin D and amyloid beta. Biochim. Biophys. Acta 1802, 198.

Elrod, J.W., Molkentin, J.D., 2013. Physiologic functions of cyclophilin D and the mitochondrial permeability transition pore. Circ. J. 77, 1111.

Fruman, D.A., Klee, C.B., Bierer, B.E., Burakoff, S.J., 1992. Calcineurin phosphatase activity in T lymphocytes is inhibited by FK 506 and cyclosporin A. Proc. Natl. Acad. Sci. U. S. A. 89, 3686

Fruman, D.A., Burakoff, S.J., Bierer, B.E., 1994. Immunophilins in protein folding and immunosuppression. FASEB J. 8, 391

Hoppert, M., Gentzsch, C., Schorgendorfer, K., 2001. Structure and localization of cyclosporin synthetase, the key enzyme of cyclosporin biosynthesis in Tolypocladium inflatum. Arch. Microbiol. 176, 285.

Ishikawa, J., Ohga, K., Yoshino, T., Takezawa, R., Ichikawa, A., Kubota, H., Yamada, T., 2003. A pyrazole derivative, YM-58483, potently inhibits store-operated sustained Ca2+ influx and IL-2 production in T lymphocytes. J. Immunol. 170, 4441.

Javadov, S., Kuznetsov, A., 2013. Mitochondrial permeability transition and cell death: the role of cyclophilin d. Front. Physiol. 4, 76.

Jiang, H., Zeng, B., Chen, G.L., Bot, D., Eastmond, S., Elsenussi, S.E., Atkin, S.L., Boa, A.N., Xu, S.Z., 2012. Effect of non-steroidal anti-inflammatory drugs and new fenamate analogues on TRPC4 and TRPC5 channels. Biochem. Pharmacol. 83, 923.

Kankaanranta, H., Luomala, M., Kosonen, O., Moilanen, E., 1996. Inhibition by fenamates of calcium influx and proliferation of human lymphocytes. Br. J. Pharmacol. 119, 487.

Kar, P., Nelson, C., Parekh, A.B., 2011. Selective activation of the transcription factor NFAT1 by calcium microdomains near Ca2+ release-activated Ca2+ (CRAC) channels. J. Biol. Chem. 286, 14795.

Kofron, J.L., Kuzmic, P., Kishore, V., Colon-Bonilla, E., Rich, D.H., 1991. Determination of kinetic constants for peptidyl prolyl cis-trans isomerases by an improved spectrophotometric assay. Biochemistry 30, 6127. 
Komárková, J.K.a.J., 2003. Freshwater algae of North America. Ecol. Classif. Kumari, S., Roy, S., Singh, P., Singla-Pareek, S.L., Pareek, A., 2013. Cyclophilins: proteins in search of function. Plant Signal. Behav. 8.

Lee, J., Kim, S.S., 2010. An overview of cyclophilins in human cancers. J. Int. Med. Res. 38, 1561

Liu, J.O., 2009. Calmodulin-dependent phosphatase, kinases, and transcriptional corepressors involved in T-cell activation. Immunol. Rev. 228, 184.

Ma, T., Gong, K., Yan, Y., Song, B., Zhang, X., Gong, Y., 2012. Mitochondrial modulation of store-operated $\mathrm{Ca}(2+)$ entry in model cells of Alzheimer's disease. Biochem. Biophys. Res. Commun. 426, 196.

Markou, G., Georgakakis, D., 2011. Cultivation of filamentous cyanobacteria (blue-green algae) in agro-industrial wastes and wastewaters: a review. Appl. Energ. 88, 3389.

Morgan, A.J., Jacob, R., 1994. Ionomycin enhances Ca2+ influx by stimulating store-regulated cation entry and not by a direct action at the plasma membrane. Biochem. J. 300 (Pt. 3), 665

Naesens, M., Kuypers, D.R., Sarwal, M., 2009. Calcineurin inhibitor nephrotoxicity. Clin. J. Am. Soc. Nephrol. 4, 481.

Nigro, P., Pompilio, G., Capogrossi, M.C., 2013. Cyclophilin A: a key player for human disease. Cell. Death. Dis. 4, e888.

Randak, C., Brabletz, T., Hergenrother, M., Sobotta, I., Serfling, E, 1990. Cyclosporin A suppresses the expression of the interleukin 2 gene by inhibiting the binding of lymphocyte-specific factors to the IL-2 enhancer. EMBO J. 9, 2529.
Sanchez, J.A., Alfonso, A., Leiros, M., Alonso, E., Rateb, M.E., Jaspars, M., Houssen, W.E., Ebel, R., Botana, L.M., 2015. Spongionella secondary metabolites regulate store operated calcium entry modulating mitochondrial functioning in SH-SY5Y neuroblastoma cells. Cell. Physiol. Biochem. 37, 779.

Smith-Garvin, J.E., Koretzky, G.A., Jordan, M.S., 2009. T cell activation. Annu. Rev. Immunol. 27, 591 .

Sweeney, Z.K., Minatti, A., Button, D.C., Patrick, S., 2009. Small-molecule inhibitors of store-operated calcium entry. ChemMedChem 4, 706.

Tornero, D., Cena, V., Gonzalez- Garcia, C., Jordan, J., 2002. The role of the mitochondrial permeability transition pore in neurodegenerative processes. Rev. Neurol. 35, 354.

Wang, P., Heitman, J., 2005. The cyclophilins. Genome Biol. 6, 226.

Watabe, M., Machida, K., Osada, H., 2000. MT-21 is a synthetic apoptosis inducer that directly induces cytochrome c release from mitochondria. Cancer Res. 60, 5214

Xiong, Y., Zhang, S., Xu, L., Song, B., Huang, G., Lu, J., Guan, S., 2013. Suppression of $\mathrm{T}$-cell activation in vitro and in vivo by cordycepin from Cordyceps militaris. J. Surg. Res. 185, 912

Zeng, B., Chen, G.L., Xu, S.Z., 2012. Store-independent pathways for cytosolic STIM1 clustering in the regulation of store-operated $\mathrm{Ca}(2+)$ influx. Biochem. Pharmacol. 84, 1024. 